\title{
Effect of gastric bypass combined with ileal transportation on type 2 diabetes mellitus
}

\author{
ZHAOXIA GAO ${ }^{1 *}$, BIN WANG $^{2 *}$, XIAOJUN GONG ${ }^{1 *}$, CHUN YAO $^{3}$, \\ DEFA REN ${ }^{1}$, LIWEI SHAO $^{1}$, YAN PANG $^{4}$ and JINXIU LIU ${ }^{1}$ \\ Departments of ${ }^{1}$ General Surgery, ${ }^{2}$ Ear-Nose-Throat, ${ }^{3}$ Endocrinology and ${ }^{4}$ Clinical Laboratory, \\ The Fifth Hospital of Wuhan, Wuhan, Hubei 430050, P.R. China
}

Received April 8, 2017; Accepted December 8, 2017

DOI: $10.3892 /$ etm.2018.5928

\begin{abstract}
Type 2 diabetes mellitus (T2DM) is a chronic progressive disease, which manifests as an endocrine disorder. Among the different methods of surgery available to treat patients with T2DM, Roux-en-Y gastric bypass (RYGBP) and ileal transposition (IT) are the most commonly performed. The aim of the present study was to investigate the effects of RYGBP combined with IT on rats with T2DM. A total of 8 healthy male rats were used as a control group and 40 GK rats were randomly divided into 5 groups: A diabetes mellitus (DM) group, a sham operative group (SO), a RYGBP group, an IT group and a RYGBP+IT group. The results demonstrated that fasting blood glucose, triglyceride, total cholesterol and gastric inhibitory polypeptide levels in all treatment groups were significantly lower than those of the SO and DM groups. Furthermore, levels TC and TG in the RYGBP+IT group were significantly lower than in the RYGBP and IT groups. Levels of phosphoenolpyruvate carboxykinase and glucose-6-phosphatase mRNA and IRS-2 protein in all treatment groups were also significantly lower than those of the SO group; and they were significantly lower in the RYGBP+IT group compared with the RYGBP and IT groups. The expression of phosphorylated Akt in the treatment groups was significantly higher than the SO group and was significantly higher in the RYGBP+IT group compared with the RYGBP and IT groups. These results indicate that RYGBP and IT surgical treatment can induce T2DM remission by mediating the expression of insulin-related factors to reverse insulin resistance. The current study also indicated that the effect of RYGBP combined with
\end{abstract}

Correspondence to: Dr Zhaoxia Gao, Department of General Surgery, The Fifth Hospital of Wuhan, 122 Xianzheng Street, Hanyang, Wuhan, Hubei 430050, P.R. China

E-mail: gao1617zx@sina.com

${ }^{*}$ Contributed equally

Key words: type 2 diabetes, gastric bypass, ileal transportation, insulin resistance
IT may be developed as a novel first-line method of treating T2DM.

\section{Introduction}

Diabetes is a chronic progressive disease that primarily manifests as an endocrine disorder (1). According to the World Health Organization, the prevalence of diabetes worldwide will reach 334 million people (2) and therefore it poses a serious threat to human health. Diabetes typically results from hyperglycaemia due to insulin resistance and a relative lack of insulin; the majority of the increased risk of mortality is attributable to associated macrovascular atherosclerotic diseases $(3,4)$. Out of all patients with diabetes, $>90 \%$ have type 2 diabetes mellitus (T2DM) (5). Currently, the most effective methods of treating T2DM are medical interventions, including surgical procedures such as Roux-en-Y gastric bypass (RYGBP) and ileal transposition (IT), anti-diabetes medication (insulin, metformin) and undergoing lifestyle changes, such as adhering to a healthy diet and partaking in regular exercise (6-8).

RYGBP surgery and IT are the most commonly performed surgical procedures to treat patients with T2DM $(9,10)$. Pories et al (11) demonstrated that, following RYGBP, blood glucose levels in patients with T2DM are more effectively regulated compared with prior to the operation. Indeed, following RYGBP, $83 \%$ of patients with T2DM exhibit normal glucose and glycated hemoglobin levels, even following discontinuation of all glucose-lowering agents (12). It is also worth noting that overweight patients exhibited normal insulin levels following RYGBP surgery, which reduced glucose levels (13). RYGBP markedly improves the prognosis of obese patients with T2DM and reduces the likelihood of complications occurring, including perioperative mortality, pulmonary embolism and dysrhythmias (11). However, a significant proportion of patients with T2DM are not obese and it remains unknown whether they can benefit from RYGBP. Previous studies have demonstrated that IT is able to induce a hypoglycemic effect in a non-obese rat model of T2DM $(10,14)$. However, the effectiveness, safety and clinical applications of IT in humans still require further clarification.

It has been reported that the expression of phosphoenolpyruvate carboxykinase (PEPCK) is upregulated in a rat model of 
diabetes and these rats are either completely lacking in insulin or exhibit increased plasma glucocorticoid levels $(15,16)$. Glucose-6-phosphatase (G-6-Pase) is the final gatekeeper of glucose efflux from cells and catalyzes the last step of gluconeogenesis (17). Previous studies have suggested that G-6-Pase contributes to the development of diabetes and its promoter has several elements in common with PEPCK (18-20). Insulin receptor substrate (IRS) proteins, including IRS-1, IRS-2 and IRS-4 also serve a critical role in the signal transduction of insulin (21). In humans, a number of polymorphisms have been identified in the IRS2 gene and these polymorphisms may increase the risk of T2DM in various populations where they are more prevalent (22).

In the present study, a T2DM rat model was used to evaluate the effects of RYGBP combined with IT on T2DM, compared with RYGBP or IT alone. Levels of diabetes-related factors, including triglyceride (TG), total cholesterol (TC), fasting blood glucose (FBG), gastric inhibitory polypeptide (GIP), glucagon-like peptide (GLP-1), PEPCK1, G-6-Pase and IRS-2, were measured and used as evaluation indicators. The primary aim of the present study was to assess the effects of RYGBP combined with IT in the treatment of non-obese T2DM, with the aim of developing a novel effective treatment of T2DM that induces T2DM remission and reduces the risk of complications occurring.

\section{Materials and methods}

Animals. A total of 40 male Goto-Kakizaki (GK) rats (age, 8 weeks; weight, $270 \pm 30 \mathrm{~g}$ ) with non-obese T2DM and 8 healthy male Sprague Dawley (SD) rats (age, 8 weeks; weight, $270 \pm 30 \mathrm{~g}$ ), were allowed to acclimate to the facility in cages for 1 week prior to experiments under a $12 \mathrm{~h}$ dark/light cycle at $22 \pm 2^{\circ} \mathrm{C}$. All rats were obtained from Shanghai SLAC Laboratory Animal Co., Ltd. (Shanghai, China). The 8 healthy rats formed the control group and the $40 \mathrm{GK}$ rats were randomly divided into the following groups (all $n=8)$ : An untreated T2DM group (DM group), a sham group, a RYGBP surgery group (RYGBP group), an IT surgery group (IT group) and an RYGBP and IT combination group (RYGBP+IT group). All protocols involving animals were approved by the Ethical Committee of the Fifth Hospital of Wuhan, Wuhan University (Wuhan, China; ethical approval no. 20160311). All dissections were performed according to recommendations proposed by the European Commission, and all efforts were made to minimize suffering in our animals.

Surgical intervention. All rats were fasted overnight for $\geq 12 \mathrm{~h}$ and then intraperitoneally anesthetized with $350 \mathrm{mg} / \mathrm{kg} 10 \%$ chloral hydrate (Sigma-Aldrich; Merck KGaA, Darmstadt, Germany). For RYGBP, the gastric bypass model was established following a previously described protocol (23). For IT surgery, Treitz's ligament was identified, the jejunum was divided $5 \mathrm{~cm}$ aborally and the ileal loop was the interpositioned in an isoperistaltic fashion, forming two end-to-end anastomoses (24). For the combination of RYGBP and IT surgery, Treitz's ligament was identified, the jejunum was divided $5 \mathrm{~cm}$ aborally and anastomoses were formed in the distal jejunum and proximal. A total of 8 male GK rats were selected to undergo sham surgery. A division of the small intestine with subsequent anastomoses was performed at the distal jejunum and proximal and ileum without IT. The sham procedure involved gastrotomy, enterotomy and repair. All rats were maintained on a standardized post-operative protocol during which a liquid diet was provided from day 2 post-surgery. During the experiment, 1 rat from the sham group, 1 rat from the RYGBP group and 2 rats from the RYGBP+IL group succumbed. This is in line with the mortality rates of rats in previous studies (25-27).

Blood and tissue collection. Blood was collected from rat tail veins prior to and 4, 8, 12 and 16 weeks following surgery. FBG levels were measured using a glucometer. Blood was then centrifuged at 2,000 x $\mathrm{g}$ for $10 \mathrm{~min}$ to separate the serum at room temperature. ELISA was then used evaluated the levels of GLP-1 and GIP and an automatic biochemical analyzer used to measure the levels of TG and TC (BS-450; Mindray, Nanshan, Shenzhen, China). All rats were euthanized via intraperitoneal administration of $150 \mathrm{mg} / \mathrm{kg}$ sodium pentobarbital (Sigma-Aldrich; Merck KGaA) 16 weeks following surgery. Liver tissue was collected and stored at $-80^{\circ} \mathrm{C}$.

ELISA. GLP-1 and GIP levels in the sera of rats were evaluated by GLP-1 (cat. no. RA20061) and GIP (cat. no. RA20389) ELISA kits obtained from Bio-Swamp Life Science (Wuhan, China) and the assay was performed in accordance with the manufacturer's protocols.

Total RNA extraction and reverse transcription-quantitative polymerase chain reaction $(R T-q P C R)$. Total RNA was extracted from liver tissue using TRIzol reagent (Takara Bio Inc., Dalian, China) and assessed using an ultraviolet spectrophotometer and $1 \%$ agarose electrophoresis. For each sample, $1 \mu \mathrm{g}$ RNA was reverse transcribed to obtain first-strand cDNA using the PrimeScript ${ }^{\circledR}$ RT reagent kit with gDNA Eraser (Takara Bio, Inc.) following the manufacturer's instructions. The reaction mixture (20 $\mu$ l total volume) contained $10 \mu \mathrm{l}$ 2X SYBR Premix Ex Taq ${ }^{\mathrm{TM}}$ (Takara Bio, Inc.), $0.5 \mu \mathrm{mol} / 1$ each primer and $0.2 \pm 0.02 \mu \mathrm{g}$ cDNA template. The following three-step qPCR reaction was performed: Pre-denaturation at $95^{\circ} \mathrm{C}$ for $30 \mathrm{sec}$, followed by 40 cycles, including denaturation at $95^{\circ} \mathrm{C}$ for $3 \mathrm{~min}$ and annealing at $60^{\circ} \mathrm{C}$ for $20 \mathrm{sec}$ and elongation at $72^{\circ} \mathrm{C}$ for $20 \mathrm{sec}$. The primes used were as follows: PEPCK forward, 5'-TCAAGTGCCTCCACTCCG-3' and reverse, 5'-GAACAAGCCCGTGTAGTCCTT-3'; G-6-Pase forward, 5'-GAAAGAATGAACGTGCTCC-3' and reverse, 5'-CAG TATCCCAACCACAAGAC-3'; $\beta$-actin forward, 5'-AGAGGG AAATCGTGCGTGAC-3' and reverse, 5'-CAATAGTGATGA CCTGGCCGT-3'. The threshold cycle (Cq) was determined for each reaction and the $\mathrm{Cq}$ values for each gene of interest were normalized to that of $\beta$-actin, which acted as a control. Levels of gene expression were then calculated using the $2^{-\Delta \Delta \mathrm{Cq}}$ method (28). For each group, three samples were measured and three technical replicates of each measurement were obtained.

Western blot analysis. Protein expression was analyzed by western blot analysis. Tissue samples were washed with PBS and homogenized at $4{ }^{\circ} \mathrm{C}$ in radioimmunoprecipitation assay lysis buffer (Beyotime Institute of Biotechnology, Haimen, China) containing protease inhibitor. Subsequently, tissues were centrifuged at $12,000 \mathrm{xg}$ for $15 \mathrm{~min}$ at $4^{\circ} \mathrm{C}$. Protein 


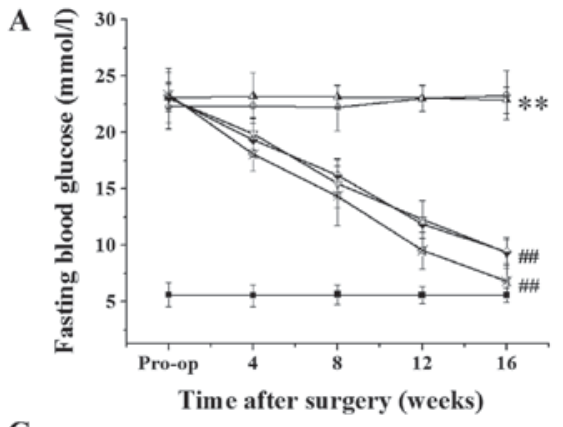

C

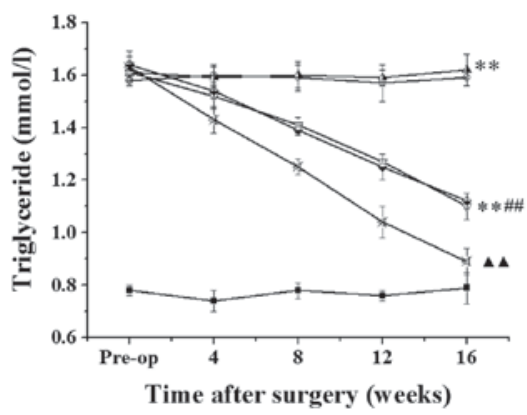

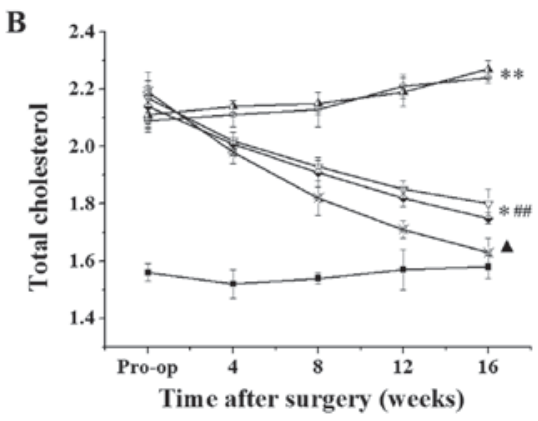

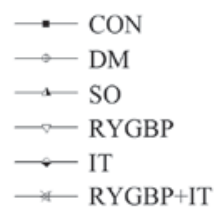

Figure 1. Levels of FBG, TC and TG of rats in each group prior to and 4, 8, 12 and 16 weeks following surgery. (A) Changes in FBG following surgery. (B) Changes in TC following surgery. (C) Changes in TG following surgery. Data are presented as the mean \pm standard error of the mean ( $=3$ ); ${ }^{*} \mathrm{P}<0.05$ and ${ }^{* *} \mathrm{P}<0.01$ vs. CON; ${ }^{\# \#} \mathrm{P}<0.01$ vs. SO; ${ }^{\boldsymbol{\Delta}} \mathrm{P}<0.05$ and ${ }^{\boldsymbol{\Delta}}{ }^{\boldsymbol{}} \mathrm{P}<0.01$ vs. IT group. CON, control group; DM, diabetes model group; SO, sham operation group; RYGBP, RYGBP surgery group; IT, ileal transposition group; RYGBP+IT, RYGBP combined with IT surgery group; RYGBP, Roux-en-Y gastric bypass; FBG, fasting blood glucose; TC, total cholesterol; TG, triglyceride.

concentration was determined using a BCA kit (Bio-Swamp Life Science). Equal amounts of protein $(30 \mu \mathrm{g})$ were separated by $10 \%$ SDS-polyacrylamide gel and then transferred onto a PVDF membrane (EMD Millipore, Billerica, MA, USA). Membranes were blocked for $2 \mathrm{~h}$ at room temperature with 5\% skim milk in Tris-buffered saline $(20 \mathrm{mmol} / 1 \mathrm{Tris}$, $500 \mathrm{mmol} / 1 \mathrm{NaCl}$ and $0.05 \%$ Tween-20). Subsequently, the membrane was incubated with primary antibodies against IRS-2 (cat. no. ab13410), Akt (cat. no. ab8805), phosphorylated (p)-Akt (cat. no. ab38449) (all dilution 1:500) and $\beta$-actin (cat. no. ab6276; dilution, 1:4,000) overnight at $4^{\circ} \mathrm{C}$ (all Abcam, Cambridge, UK). $\beta$-actin was used as an internal reference. Membranes were subsequently washed with Tris-buffered saline and incubated with goat anti-rabbit secondary antibody conjugated to horseradish peroxidase (cat. no. W4011; dilution, 1:3,000; Promega Corporation, Madison, WI, USA) for $2 \mathrm{~h}$ at room temperature. Immunoreactivity was visualized via a colorimetric reaction using enhanced chemiluminscent substrate buffer (EMD Millipore). Membranes were analyzed using a Gel Doc EZ imager and bans were quantified using Quantity One 5.0 (Bio-Rad Laboratories, Hercules, CA, USA).

Statistical analysis. SPSS 19.0 software (IBM Corp, Armonk, NY, USA) was used for data analysis and statistical differences were detected using one-way analysis of variance followed by Dunnett's post hoc test. All values were expressed as the mean \pm standard error mean. Differences were considered to be statistically significant at $\mathrm{P}<0.05$.

\section{Results}

Surgical treatment regulates hyperglycemia and decreases $T C$ and TG levels in the blood of T2DM rats. FGB, TC and
TG were evaluated in each of the groups prior to and 4, 8, 12 and 16 weeks following surgery. FBG, TC and TG levels in all treatment groups were higher than those of the control group prior to surgery (Fig. 1). However 16 weeks following surgery, FBG, TC and TG levels in the RYGBP, IT and RYGBP+IT groups were significantly decreased compared with the sham and DM groups. Notably, TC and TG levels in the RYGBP+IT group were significantly lower than those in the RYGBP and IT groups 16 weeks following surgery.

Surgical treatment decreases GIP and GLP-1 levels in the serum of T2DM rats. GIP and GLP-1 levels in the serum of rats were determined using ELISA (Fig. 2). GIP levels in all rats with T2DM were increased significantly compared with the control group prior to surgery. However, 16 weeks following surgery, GIP levels in the RYGBP, IT and RYGBP+IT groups were significantly lower than those of the DM and sham groups (Fig. 2A). GLP-1 levels in the rats with T2DM were significantly decreased compared with control group prior to surgery. However, 16 weeks following surgery, GLP-1 levels in the RYGBP, IT and RYGBP+IT groups were significantly higher than those of the DM, sham and control groups (Fig. 2B). GLP-1 levels in the sham and DM groups remained significantly lower than those of the control.

Surgical treatment reduces the mRNA expression levels of PEPCK and G-6-Pase in the liver of T2DM rats. The mRNA expression levels of PEPCK and G-6-Pase in the liver of rats were evaluated using RT-qPCR. Compared with the control group, mRNA levels of PEPCK and G-6-Pase in the DM, sham, RYGBP and IT groups were significantly increased (Fig. 3). However, compared with the sham group, the mRNA 


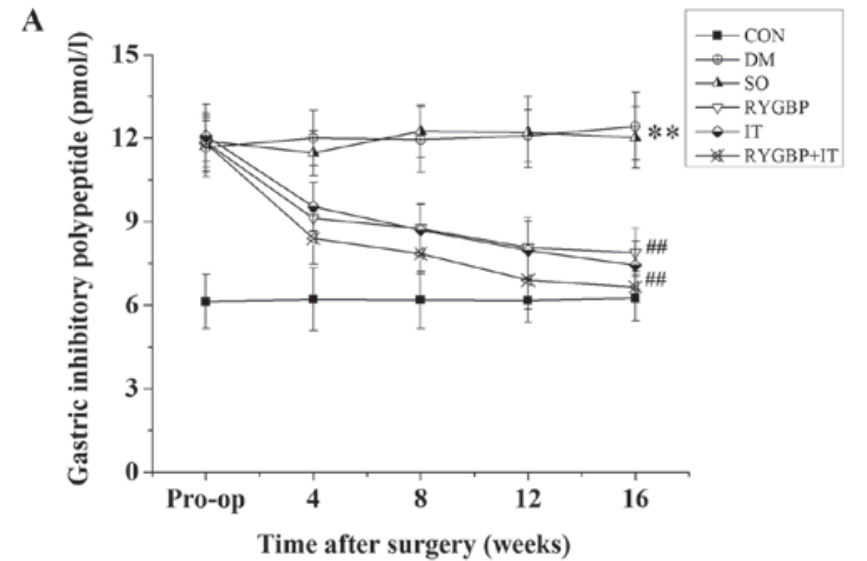

B

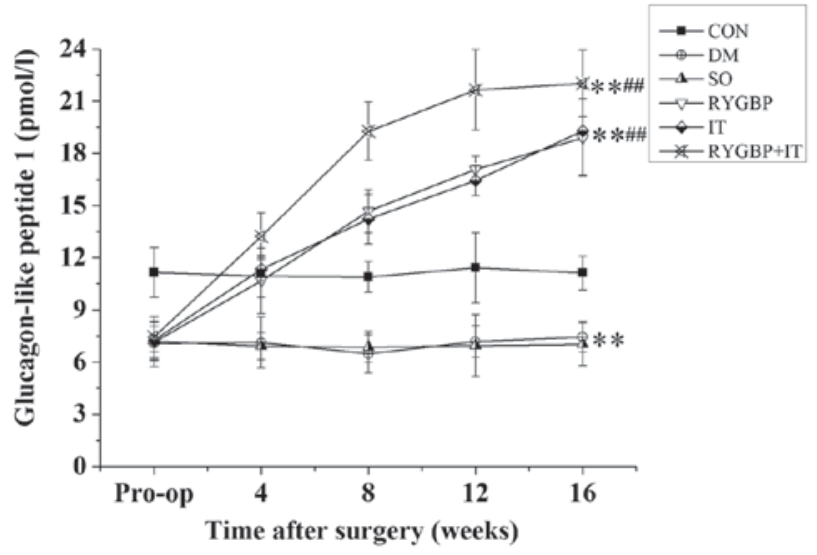

Figure 2. GIP and GLP-1 levels in rats from each group prior to and 4, 8, 12 and 16 weeks following surgery. (A) Changes in GIP levels in rats following surgery. (B) Changes in GLP-1 levels in rats following surgery. Data are presented as the mean \pm standard error of the mean $(n=3) ;{ }^{* *} \mathrm{P}<0.01$ vs. $\mathrm{CON}$ group, ${ }^{\# \#} \mathrm{P}<0.01$ vs. SO group. CON, control group; DM, diabetes model group; SO, sham operation group; RYGBP, RYGBP surgery group; IT, ileal transposition group; RYGBP+IT, RYGBP combined with IT surgery group; RYGBP, Roux-en-Y gastric bypass; GIP, gastric inhibitory polypeptide; GLP-1, glucagon-like peptide.

levels of PEPCK and G-6-Pase in the RYGBP and IT groups were decreased significantly. Furthermore, compared with the IT group, the mRNA levels of PEPCK and G-6-Pase in the RYGBP+IT group were significantly decreased and were similar to those of the control group.

Surgical treatment reduces the protein levels of IRS-2 and $p$-Akt in the liver of T2DM rats. Levels of IRS2, Akt and $\mathrm{p}$-Akt protein in the liver of rats were evaluated by western blotting (Fig. 4A). Compared with control group, the expression of IRS-2 in the DM, sham, RYGBP and IT groups were increased significantly (Fig. 4B). However, compared with the DM group, IRS-2 expression in the RYGBP and IT groups were significantly decreased. Furthermore, IRS-2 expression in the RYBGP+IT group was significantly lower than that of the RYBGP and IT groups. p-Akt expression in the DM, sham, RYGBP and IT groups was significantly lower than in the control group; however, p-Akt expression in the RYGBP and IT groups was significantly increased compared with the sham group. In addition, p-Akt expression in the RYGBP+IT group was significantly higher than that of the RYBGP or IT groups. Akt expression did not differ significantly among any of the groups.

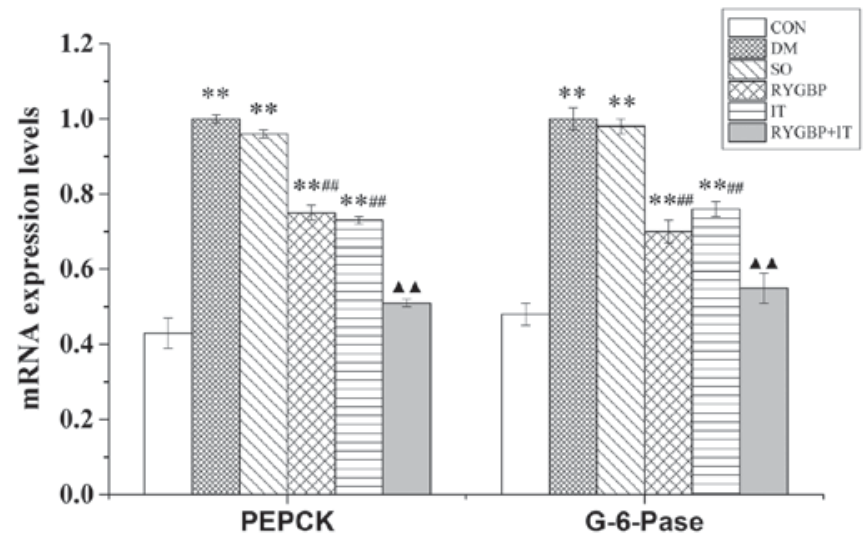

Figure 3. The mRNA expression of PEPCK and G-6-Pase of rats from each group 16 weeks following surgery. Data are presented as the mean \pm standard error of the mean $(n=3) .{ }^{* *} \mathrm{P}<0.01$ vs. CON group, ${ }^{\# \#} \mathrm{P}<0.01$ vs. SO group, ${ }^{\triangle \wedge} \mathrm{P}<0.01$ vs. IT group. CON, control group; DM, diabetes model group; SO, sham operation group; RYGBP, RYGBP surgery group; IT, ileal transposition group; RYGBP+IT, RYGBP combined with IT surgery group; PEPCK, phosphoenolpyruvate carboxykinase; G-6-pase, Glucose-6-phosphatase.

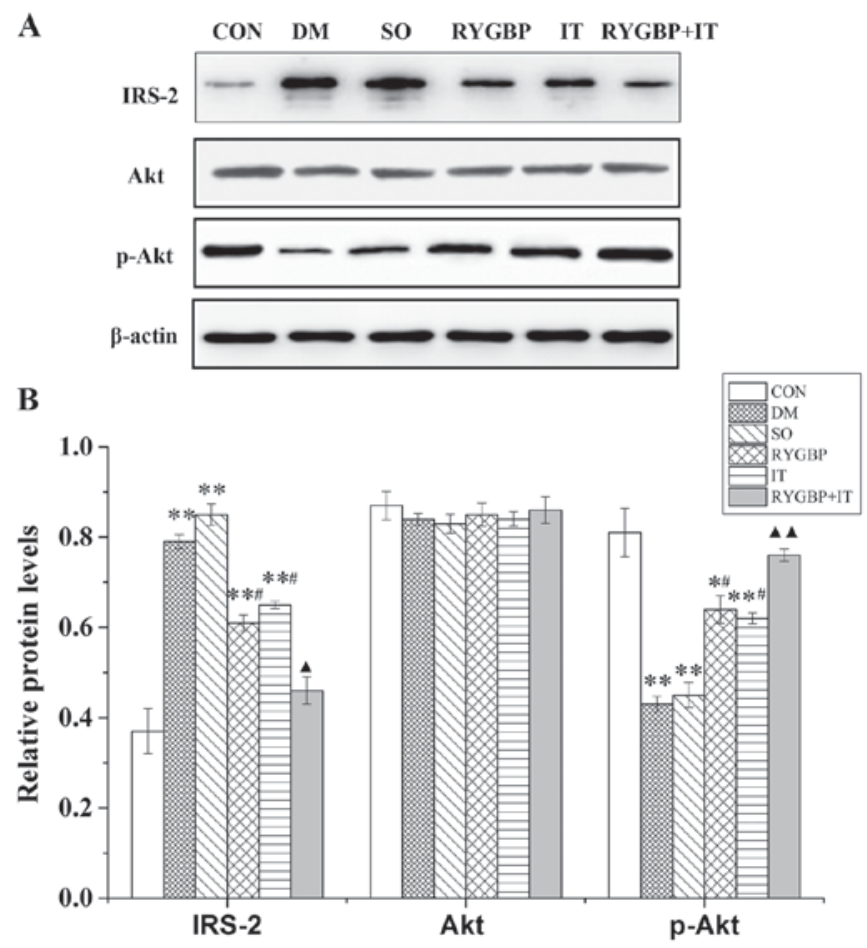

Figure 4. The expression of IRS-2, Akt and p-Akt proteins in rats from each group 16 weeks following surgery. (A) Representative western blots and (B) quantification of western blotting results. Data are presented as the mean \pm standard error of the mean $(\mathrm{n}=3) ;{ }^{*} \mathrm{P}<0.05$ or ${ }^{* * *} \mathrm{P}<0.01$ vs. $\mathrm{CON}$ group, ${ }^{\#} \mathrm{P}<0.05$ vs. SO group, ${ }^{\mathbf{\Delta}} \mathrm{P}<0.05$ or ${ }^{\boldsymbol{\Delta}}{ }^{\wedge} \mathrm{P}<0.01$ vs. IT group. CON, control group; DM, diabetes model group; SO, sham operation group; RYGBP, RYGBP surgery group; IT, ileal transposition group; RYGBP+IT, RYGBP combined with IT surgery group; RYGBP, Roux-en-Y gastric bypass; IRS-2, insulin receptor substrate 2 .

\section{Discussion}

Diabetes is chronic metabolic disease characterized by hyperglycemia that is induced by defects in insulin secretion or activity (1). T2DM is the most common type of clinical diabetes. At present, the pathogenesis of T2DM has not been 
fully elucidated; however its primary clinical features, which are insulin resistance and $\beta$ cell dysfunction, have been identified (29). Medication to treat patients with diabetes aims to achieve glycemic control and reduce the risk of associated complications arising; this differs from the desired end-point following metabolic surgery, which is euglycemia (30). It has been demonstrated that metabolic surgery is able to effectively regulate T2DM and obesity (31). Although innovative procedures to treat diabetes are being investigated,including the novel anti-diabetic drugs, DDP-4 inhibitor and SGLT-2 inhibitor, as well as surgical treatment by laparoscopic sleeve gastrectomy, RYGBP and IT, their precise mechanisms of action remain to be elucidated $(32,33)$. In the present study, the effects of three surgical treatments on a rat model of T2DM were investigated. Levels of insulin metabolism-related genes and proteins were used to assess the effect of surgery on T2DM.

Buchwald et al (12) reported that RYGBP surgery can regulate glycosylated hemoglobin and FBG in obese patients and may also alleviate symptoms of the disease, including hypertension, hyperlipidemia and gastroesophageal reflux. Furthermore, Pories et al (11) demonstrated that the treatment efficiency of RYGBP on T2DM may reach $99 \%$. The results of the present study demonstrated that RYGBP and IT significantly decrease levels of FBG, TC and TG in rats with T2DM and indicated that these decreases were more significant in rats that underwent RYGBP combined with IT. GIP is a member of the glucagon peptide superfamily, which is secreted by $\mathrm{K}$ cells that are distributed throughout the proximal digestive tract. The main roles of GIP are to promote the secretion of insulin, increase sensitivity to insulin and induce secretion of GLP-1 (34). Previous studies have reported that GIP receptor gene knockout reduces the efficacy of GIP and therefore promotes insulin resistance, indicating that GIP may serve an important role in the development of T2DM $(35,36)$. The results of the current study indicated that surgical treatment significantly decreased GIP levels in rats with T2DM and also reduced blood glucose levels. This indicates that the low secretion of GIP caused by the digestion of food without the involvement of the proximal small intestine may serve an important role in the surgical treatment of T2DM.

GLP-1 is a core mediator in the intestine-islet axis regulation of T2DM (37). RYGBP surgery induces a decrease in FBG, which is accompanied by an increase in GLP-1 and a decrease in insulin resistance (38). In the present study, GLP-1 levels in T2DM rats were significantly decreased compared with the control group. However, following surgical treatment, GLP-1 levels were significantly increased and GLP-1 levels in the RYGBP+IT group were significantly higher than in the RYGBP and IT groups. This indicates that surgical treatment can induce GLP-1 release to exert a hypoglycemic effect and the RYGBP+IT surgery is the most effective method of achieving this. The results of the present study are in accordance with a study by Patriti et al (39), which reported that IT surgery significantly improved glucose tolerance and reduced insulin resistance in GK rats.

T2DM primarily manifests as abnormally elevated FBG, caused by glucagon regulation of liver gluconeogenesis $(40,41)$. Research has demonstrated that glucagon is able to promote liver gluconeogenesis by regulating the expression of key enzymes, including PEPCK and G-6-Pase; dysregulation of these enzymes may stimulate the development of glucose metabolism disorders (17). In the present study, PEPCK and G-6-Pase mRNA levels were significantly increased in the liver of rats with T2DM, in contrast to previous studies, which demonstrated that the expression of G-6-Pase and PEPCK is not increased in rats with T2DM $(17,42)$. Notably, in the current study, PEPCK and G-6-Pase mRNA levels decreased significantly in rats following surgical treatment. Furthermore, PEPCK and G-6-Pase mRNA levels in rats treated with RYGBP combined with IT were significantly lower than in rats treated with RYGBP or IT alone. In G-6-Pase-deficient mice, adenoviral rescue with the G-6-Pase gene suggests that even a fraction of phosphatase activity allows mice to maintain normal plasma glucose levels (43). This suggests that surgical treatment may promote plasma glucose levels by regulating PEPCK and G-6-Pase.

The current study also demonstrated that RYGBP combined with IT treatment significantly decreased IRS-2 expression and increased p-Akt expression in rats with T2DM. IRS-2 is highly expressed in insulin sensitive tissues and serves a critical role in insulin-signaling pathway (44). At the molecular level, IRS-2 deficiency results in impaired insulin-mediated Akt phosphorylation, despite intact IR and IRS-1 tyrosine phosphorylation responses (45). Akt activation may promote the inhibitory effect of insulin resistance on T2DM by stimulating glucose transfer, glycogen synthesis, fat deposition and protein synthesis (46). IRS-2 knockout mice exhibit characteristics of T2DM and a reduction in IRS-2 phosphorylation may also induce insulin resistance $(47,48)$. These results demonstrate that IRS-2 serves an important role in the development of insulin resistance and T2DM. Previous studies have also demonstrated that Akt activation is decreased in Lepr (db/+) mice with spontaneous gestational diabetes mellitus, leading to an increase in the expression G-6-Pase and the inhibition of hepatic glycogen production in the offspring of these mice $(49,50)$. The results of the current study indicate that RYGBP and IT surgical treatment decrease the expression of PEPECK, G-6-Pase and IRS-2, and increase the expression of p-Akt in the liver of T2DM rats. Furthermore, the regulation of insulin signaling pathway related factors was most effective in rats treated with RYGBP and IT. This indicates that treatment with RYGBP and IT may stimulate T2DM remission by regulating the insulin signaling pathway to inhibit insulin resistance.

In conclusion, the present study used RYGBP combined with IT surgery to treat mice with T2DM and the results demonstrated that it more effectively promoted the remission of T2DM compared with RYGBP or IT surgery alone. Additionally, RYGBP combined with IT may mediate the insulin-signaling pathway by regulating the expression of associated factors to induce T2DM remission.

\section{Acknowledgements}

Not applicable.

\section{Funding}

The current study was supported by a grant from the Health and Family Planning Commission of Wuhan, China (grant no. WX11B12). 


\section{Availability of data and materials}

All datasets used during the current study are available from the corresponding author on reasonable request.

\section{Author contributions}

$\mathrm{ZG}$ designed the experiment, gave final approval of the version to be published and was responsible for the acquisition of funding. BW collected the blood and tissue samples, performed the ELISA assay and critically revised the manuscript. XG analyzed the data regarding blood index. CY measured the expression of associated mRNA using RT-qPCR. DR detected the expression levels of associated proteins using western blotting. LS contributed to the design of the present study and was a major contributor in writing the manuscript. YP analyzed the data regarding the expression of associated mRNA and proteins. JL was involved in drafting the manuscript and performed the surgical intervention for rats. All authors read and approved the final manuscript.

\section{Ethics approval and consent to participate}

The study protocol was approved by the Ethical Committee of the Fifth Hospital of Wuhan, Wuhan University (Wuhan, China; ethical approval no. 20160311).

\section{Consent for publication}

Not applicable.

\section{Competing interests}

The authors confirm that they have no competing interests.

\section{References}

1. Zhang P, Zhang H, Han X, Di J, Zhou Y, Li K and Zheng QI: Effectiveness and safety of laparoscopic Roux-en-Y gastric bypass for the treatment of type 2 diabetes mellitus. Exp Ther Med 11: 827-831, 2016.

2. Wild S, Roglic G, Green A, Sicree R and King H: Global prevalence of diabetes: Estimates for the year 2000 and projections for 2030. Diabetes Care 27: 1047-1053, 2004.

3. Cunningham CM, Larzelere ED and Arar I: Conventional microscopy vs. computer imagery in chiropractic education. J Chiropr Educ 22: 138-144, 2008.

4. Mocanu AO, Mulya A, Huang H, Dan O, Shimizu H, Batayyah E, Brethauer SA, Dinischiotu A and Kirwan JP: Effect of Roux-en-Y gastric bypass on the NLRP3 inflammasome in adipose tissue from obese rats. PLoS One 10 e0139764, 2015.

5. Wild S, Roglic G, Green A, Sicree R and King H: Global prevalence of diabetes: Estimates for the year 2000 and projections for 2030. Diabetes Care 27: 1047-1053, 2004.

6. Boza C, Muñoz R, Salinas J, Gamboa C, Klaassen J, Escalona A, Pérez G, Ibañez L and Guzmán S: Safety and efficacy of Roux-en-Y gastric bypass to treat type 2 diabetes mellitus in non-severely obese patients. Obes Surg 21: 1330-1336, 2011.

7. Gloy VL, Briel M, Bhatt DL, Kashyap SR, Schauer PR, Mingrone G, Bucher HC and Nordmann AJ: Bariatric surgery versus non-surgical treatment for obesity: A systematic review and meta-analysis of randomised controlled trials. BMJ 347 : f5934, 2013 .
8. Jørgensen CH, Gislason GH,Andersson C, Ahlehoff O, Charlot M, Schramm TK, Vaag A, Abildstrøm SZ, Torp-Pedersen C and Hansen PR: Effects of oral glucose-lowering drugs on long term outcomes in patients with diabetes mellitus following myocardial infarction not treated with emergent percutaneous coronary intervention-a retrospective nationwide cohort study. Cardiovasc Diabetol 9: 54, 2010.

9. Buchwald $\mathrm{H}$ and Williams SE: Bariatric surgery worldwide 2003. Obes Surg 14: 1157-1164, 2004.

10. DePaula AL, Macedo AL, Mota BR and Schraibman V: Laparoscopic ileal interposition associated to a diverted sleeve gastrectomy is an effective operation for the treatment of type 2 diabetes mellitus patients with BMI 21-29. Surg Endosc 23: 1313-1320, 2009.

11. Pories WJ, Swanson MS, MacDonald KG, Long SB Morris PG, Brown BM, Barakat HA, deRamon RA, Israel G, Dolezal JM, et al: Who would have thought it? An operation proves to be the most effective therapy for adult-onset diabetes mellitus. Ann Surg 222: 339-352, 1995.

12. Buchwald H, Avidor Y, Braunwald E, Jensen MD, Pories W, Fahrbach K and Schoelles K: Bariatric surgery: A systematic review and meta-analysis. JAMA 292: 1724-1737, 2004.

13. Schauer PR, Burguera B, Ikramuddin S, Cottam D, Gourash W, Hamad G, Eid GM, Mattar S, Ramanathan R, Barinas-Mitchel E, et al: Effect of laparoscopic Roux-en Y gastric bypass on type 2 diabetes mellitus. Ann Surg 238: 467-485, 2003.

14. Wang TT, Hu SY, Gao HD, Zhang GY, Liu CZ, Feng JB and Frezza EE: Ileal transposition controls diabetes as well as modified duodenal jejunal bypass with better lipid lowering in a nonobese rat model of type II diabetes by increasing GLP-1. Ann Surg 247: 968-975, 2008.

15. Robinson SW, Dinulescu DM and Cone RD: Genetic models of obesity and energy balance in the mouse. Annu Rev Genet 34: $687-745,2000$

16. Wu J, Hou SS, Wang W, Yin M, Cheng N, Ge LL, Yin JJ and $\mathrm{Xu}$ J: Hepatic phosphoenolpyruvate carboxykinase expression after gastric bypass surgery in rats with type 2 diabetes mellitus. Genet Mol Res 14: 16938-16947, 2015.

17. Samuel VT, Beddow SA, Iwasaki T, Zhang XM, Chu X, Still CD, Gerhard GS and Shulman GI: Fasting hyperglycemia is not associated with increased expression of PEPCK or G6Pc in patients with type 2 diabetes. Proc Natl Acad Sci USA 106: 12121-12126, 2009.

18. Vander Kooi BT, Onuma H, Oeser JK, Svitek CA, Allen SR, Vander Kooi CW, Chazin WJ and O'Brien RM: The glucose-6phosphatase catalytic subunit gene promoter contains both positive and negative glucocorticoid response elements. Mol Endocrinol 19: 3001-3022, 2005.

19. Haber BA, Chin S, Chuang E, Buikhuisen W, Naji A and Taub R: High levels of glucose-6-phosphatase gene and protein expression reflect an adaptive response in proliferating liver and diabetes. J Clin Invest 95: 832-841, 1995.

20. Liu Z, Barrett EJ, Dalkin AC, Zwart AD and Chou JY: Effect of acute diabetes on rat hepatic glucose-6-phosphatase activity and its messenger RNA level. Biochem Biophys Res Commun 205: 680-686, 1994.

21. Sesti G, Federici M, Hribal ML, Lauro D, Sbraccia P and Lauro R: Defects of the insulin receptor substrate (IRS) system in human metabolic disorders. FASEB J 15: 2099-2111, 2001.

22. Bjornholm M, Kawano Y, Lehtihet M and Zierath JR: Insulin receptor substrate-1 phosphorylation and phosphatidylinositol 3-kinase activity in skeletal muscle from NIDDM subjects after in vivo insulin stimulation. Diabetes 46: 524-527, 1997.

23. Gatmaitan P, Huang H, Talarico J, Moustarah F, Kashyap S, Kirwan JP, Schauer PR and Brethauer SA: Pancreatic islet isolation after gastric bypass in a rat model: Technique and initial results for a promising research tool. Surg Obes Relat Dis 6: 532-537, 2010

24. Stygar D, Sawczyn T, Skrzep-Poloczek B, Karcz-Socha I, Doleżych B, Zawisza-Raszka A, Augustyniak M, ŻwirskaKorczala K and Karcz WK: Ileal transposition in rats influenced glucose metabolism and HSP70 levels. Open Life Sci 10: 278-284, 2015.

25. Kodama Y, Zhao CM, Kulseng B and Chen D: Eating behavior in rats subjected to vagotomy, sleeve gastrectomy, and duodenal switc. J Gastrointest Surg 14: 1502-1510, 2010.

26. Huang S, Jiao YB, Wang Y, Zou ZD, Zhang ZZ, Wang YB and Dai LJ: Long-term efficacy of gastric bypass on non-obese type 2 diabetes mellitus in Goto-Kakizaki rat. Chin J Clin 5, 2011. 
27. Yin DP, Gao Q, Ma LL, Yan W, Williams PE, McGuinness OP, Wasserman DH and Abumrad NN: Assessment of different bariatric surgeries in the treatment of obesity and insulin resistance in mice. Ann Surg 254: 73-82, 2011.

28. Livak KJ and Schmittgen TD: Analysis of relative gene expression data using real-time quantitative PCR and the 2(-Delta Delta C(T)) method. Methods 25: 402-408, 2001.

29. Lupi R and Del Prato S: Beta-cell apoptosis in type 2 diabetes: Quantitative and functional consequences. Diabetes Metab 34 (Suppl 2): S56-S64, 2008.

30. Rubino F, Schauer PR, Kaplan LM and Cummings DE: Metabolic surgery to treat type 2 diabetes: Clinical outcomes and mechanisms of action. Annu Rev Med 61: 393-411, 2010.

31. Schauer PR, Bhatt DL, Kirwan JP, Wolski K, Brethauer SA, Navaneethan SD, Aminian A, Pothier CE, Kim ES, Nissen SE, et al: Bariatric surgery versus intensive medical therapy for diabetes-3-year outcomes. N Engl J Med 370: 2002-2013, 2014.

32. Cohen RV, Schiavon CA, Pinheiro JS, Correa JL and Rubino F: Duodenal-jejunal bypass for the treatment of type 2 diabetes in patients with body mass index of $22-34 \mathrm{~kg} / \mathrm{m}^{2}$ : A report of 2 cases. Surg Obes Relat Dis 3: 195-197, 2007.

33. Müller-Stich BP, Senft JD, Warschkow R, Kenngott HG Billeter AT, Vit G, Helfert S, Diener MK, Fischer L, Büchler MW and Nawroth PP: Surgical versus medical treatment of type 2 diabetes mellitus in nonseverely obese patients: A systematic review and meta-analysis. Ann Surg 261: 421-429, 2015.

34. Vilsbøll T: On the role of the incretin hormones GIP and GLP-1 in the pathogenesis of Type 2 diabetes mellitus. Dan Med Bull 51: 364-370, 2004

35. Miyawaki K, Yamada Y, Ban N, Ihara Y, Tsukiyama K, Zhou H, Fujimoto S, Oku A, Tsuda K, Toyokuni S, et al: Inhibition of gastric inhibitory polypeptide signaling prevents obesity. Nat Med 8: 738-742, 2002.

36. Gault VA, Mcclean PL, Cassidy RS, Irwin N and Flatt PR: Chemical gastric inhibitory polypeptide receptor antagonism protects against obesity, insulin resistance, glucose intolerance and associated disturbances in mice fed high-fat and cafeteria diets. Diabetologia 50: 1752-1762, 2007.

37. Aylwin S: Gastrointestinal surgery and gut hormones. Curr Opin Endocrinol Diabetes Obes 12: 89-98, 2005

38. Meirelles K, Ahmed T, Culnan DM, Lynch CJ, Lang CH and Cooney RN: Mechanisms of glucose homeostasis after Roux-en-Y gastric bypass surgery in the obese, insulin-resistant Zucker rat. Ann Surg 249: 277-285, 2009.
39. Patriti A, Facchiano E, Annetti C, Aisa MC, Galli F, Fanelli C and Donini A: Early improvement of glucose tolerance after ileal transposition in a non-obese type 2 diabetes rat model. Obes Surg 15: 1258-1264, 2005

40. Hancock AS, Du A, Liu J, Miller M and May CL: Glucagon deficiency reduces hepatic glucose production and improves glucose tolerance in adult mice. Mol Endocrinol 24: 1605-1614, 2010.

41. Jecht M: Leptintherapie bei Typ-1-diabetes-bedingtem insulinmangel. Der Diabetologe 6: 214-216, 2010.

42. Muñoz MC, Barberà $\mathrm{A}$, Domínguez $\mathrm{J}$, Fernàndezalvarez $\mathrm{J}$, Gomis R and Guinovart JJ: Effects of tungstate, a new potential oral antidiabetic agent, in Zucker diabetic fatty rats. Diabetes 50: 131-138, 2001.

43. Zingone A, Hiraiwa H, Pan CJ, Lin B, Chen H, Ward JM and Chou JY: Correction of glycogen storage disease type 1a in a mouse model by gene therapy. J Biol Chem 275: 828-832, 2000.

44. White MF: IRS2 integrates insulin/IGF1 signalling with metabolism, neurodegeneration and longevity. Diabetes Obes Metab 16 (Suppl 1): S4-S15, 2014.

45. Santamaria B, Marquez E, Lay A, Carew RM, GonzálezRodríguez Á, Welsh GI, Ni L, Hale LJ, Ortiz A, Saleem MA, et al: IRS2 and PTEN are key molecules in controlling insulin sensitivity in podocytes. Biochim Biophys Acta 1853: 3224-3234, 2015.

46. Patti ME, Houten SM, Bianco AC, Bernier R, Larsen PR, Holst JJ, Badman MK, Maratos-Flier E, Mun EC, Pihlajamaki J, et al: Serum bile acids are higher in humans with prior gastric bypass: Potential contribution to improved glucose and lipid metabolism. Obesity (Silver Spring) 17: 1671-1677, 2009.

47. Withers DJ, Gutierrez JS, Towery H, Burks DJ, Ren JM, Previs S, Zhang Y, Bernal D, Pons S, Shulman GI, et al: Disruption of IRS-2 causes type 2 diabetes in mice. Nature 391: 900-904, 1998.

48. Kubota N, Tobe K, Terauchi Y, Eto K, Yamauchi T, Suzuki R, Tsubamoto Y, Komeda K, Nakano R, Miki H, et al: Disruption of insulin receptor substrate 2 causes type 2 diabetes because of liver insulin resistance and lack of compensatory beta-cell hyperplasia. Diabetes 49: 1880-1889, 2000.

49. Shao J, Yamashita H, Qiao L and Friedman JE: Decreased Akt kinase activity and insulin resistance in C57BL/KsJ-Leprdb/db mice. J Endocrinol 167: 107-115, 2000

50. Yamashita H, Shao J, Qiao L, Pagliassotti M and Friedman JE: Effect of spontaneous gestational diabetes on fetal and postnatal hepatic insulin resistance in Lepr(db/+) mice. Pediatr Res 53: 411-418, 2003. 